\title{
Customer-based Brand Equity de Destinos Turísticos: um estudo sobre Foz do Iguaçu
}

\author{
Customer-based tourism destiny brand equity: Foz do Iguaçu case
}

\section{Customer-based Brand Equity de Destinos Turísticos: un estudio sobre Foz do Iguaçu}

\author{
Maria Isabel da Silva Teles ${ }^{1}$ \\ Eliane Cristine Francisco Maffezzolli ${ }^{2}$ \\ Paulo Henrique Muller Prado ${ }^{3}$
}

\begin{abstract}
Resumo
Este trabalho tem por objetivo mensurar o valor de marca de destinos turísticos de acordo com a percepção do consumidor/turista. Para tanto, como contexto empírico do estudo foi realizado um survey na localidade turística de Foz do Iguaçu com 286 casos válidos. Quatro dimensões foram analisadas, sendo elas: o conhecimento de marca, a lealdade à marca, a qualidade percebida e os atrativos turísticos do destino em análise. Os resultados sugerem a existência de dois grupos distintos na amostra: (1) um grupo com percepção altamente positiva da localidade, chamado de "fascinados", e (2) um grupo com percepção média ou indiferente quanto ao objeto de estudo, chamado de "indiferentes". O valor percebido da marca do destino Foz do Iguaçu demonstrou ser diferente entre os grupos de turista, mas reforçou a necessidade de se explorar a imagem dos atrativos naturais da localidade, em prol da disseminação do conhecimento do destino perante os diferentes públicos.
\end{abstract}

Palavras-chave: gestão de marcas de destinos turísticos; valor de marca de destinos turísticos do ponto de vista do consumidor; marcas.

\section{Abstract}

The objective of this work is to measure costumer-based brand equity of tourism destinations. As an empirical context for this study, a survey was performed in Foz do Iguacu, with 286 valid cases. Four dimensions were analyzed: knowledge of the brand; loyalty to the brand, perceived quality and the touristic attractions of the destination under analysis. The results suggest the existence of two distinct groups in the sample: (1) a group displaying a very high perception of the location, thus called "fascinated", and (2) a group with average or indifferent perception of the object under study, thus called "indifferent". Foz do Iguacu's

\footnotetext{
${ }^{1}$ Mestre em Administração pela Universidade Federal do Paraná; Bacharel em Comunicação Social e professora na área de Comunicação Social da União Dinâmica de Faculdades Cataratas - Paraná. E-mail: mabel@cybermais.net.

${ }^{2}$ Doutora e Mestre em Administração pela Universidade Federal do Paraná; Professora Ajunta do PPAD da PUCPR. E-mail: eliane.francisco@pucpr.br.

${ }^{3}$ Professor Adjunto de Marketing PPGADM-DAGA-UFPR. E-mail: pprado@ufpr.br.
} 
brand equity as a tourism destination was different for each tourist group, but the analysis emphasized the need to explore the image of the natural attractions of the site in order to disseminate the knowledge of the destination for both publics.

Keywords: management of tourism destination brands; customer-based brand equity of tourism destination; brands.

\section{Resumen}

Este trabajo tiene por objetivo mensurar el valor de marca de destinos turísticos de acuerdo con la percepción del consumidor/turista. Para esto, como contexto empírico del estudio fue realizado un survey en la localidad turística de Foz do Iguaçu, con 286 casos válidos. Cuatro dimensiones fueron analizadas, siendo ellas: el conocimiento de marca, la lealtad a la marca, la cualidad percibida y los atractivos turísticos del destino en análisis. Los resultados sugieren la existencia de dos grupos en la muestra: (1) un grupo con percepción altamente positiva de la localidad, llamado "fascinados", y (2) un grupo con percepción media o indiferente en cuanto al objeto de estudio, llamado de "indiferentes". El valor percibido de la marca del destino turístico analizado demostró ser diferente entre los grupos, mas reforzó la necesidad de explorar la imagen de atractivos naturales en pro de diseminar el conocimiento del destino ante los diferentes públicos.

Palabras-clave: gestión de marcas de destinos turísticos; valor de marca de destinos turísticos del punto de vista del consumidor; marcas

\section{Introdução}

O turismo apresenta-se no cenário contemporâneo como importante atividade para o desenvolvimento da economia mundial, bem como para a geração de renda sustentável para diversas nações do mundo. O Fórum Econômico Mundial estima, inclusive, que esse é o setor econômico que mais cresce no mundo (EMBRATUR, 2009).

Esta área de estudo sofre influência da globalização, com padrões, idiomas, moedas e empresas multinacionais atuantes em todo o desenvolvimento turístico, gerando, consequentemente, forte aumento na concorrência entre os produtos, ou seja, dos destinos turísticos. Assim, na busca por parcelas crescentes de market share, os destinos turísticos têm sido encorajados a criarem identidade única e encontrarem nicho específico de modo a diferenciarem-se de seus concorrentes (RITCHIE; CROUNCH, 2003; MORGAN; PRITCHARD; PIGGOTT, 2002). 
Nesta perspectiva, o estudo do valor percebido de marca do ponto de vista do consumidor/turista, ou customer-based brand equity (CBBE), tem ganhado ênfase no âmbito do marketing de destinos (KONECNIK, 2006; KONECNIK; GARTNER, 2007; BOO, 2006). O CBBE é considerado uma importante ferramenta estratégica para o conhecimento das dimensões críticas que compõem a marca de determinada localidade, facilitando assim a gestão da marca do destino. Em segundo lugar, a mensuração do CBBE contribui com a identificação dos principais ativos do destino, facilitando a criação de estratégias de posicionamento e de comunicação da localidade (BOO, 2006). Além disso, é consenso entre muitos autores que a marca é capaz de gerar vantagem competitiva para as organizações (KAPFERER, 2003; KELLER; MACHADO, 2006; AAKER, 1998), item relevante ao se considerar mercados competitivos, como é o caso do turismo.

Apesar da importância do assunto e dos contínuos esforços dos pesquisadores da área, ainda não há consenso na literatura sobre um modelo único para mensurar o valor de marca sob a perspectiva do consumidor (AAKER, 1998; KELLER, 1993; e YOO; DONTHU, 1999). Na pesquisa do valor de marca de destinos turísticos esta realidade é mais presente, visto que o construto destino turístico é ainda mais multidimensional do que os produtos manufaturados e outros tipos de serviços (BOO; BUSSER; BALOGLU, 2009).

Além disso, importa considerar que as pesquisas sobre marcas de destinos turísticos ainda são insuficientes, uma vez que excluindo a farta pesquisa sobre a dimensão imagem de destinos (CAI, 2002; GALLARZA et al, 2002; HANKINSON, 2004; O'LEARY, 2005; PREBENSEN, 2006;) as demais dimensões do CBBE de um destino turístico têm sido escassamente pesquisadas (KONECNIK, 2006). Tal realidade proporciona fértil campo para novas pesquisas na área.

Neste contexto, o presente artigo objetiva avaliar o valor da marca do destino turístico Foz do Iguaçu do ponto de vista do turista brasileiro, a partir da adaptação de um modelo teórico de CBBE desenvolvido e testado por Konecnik (2006) e Konecnik e Gartner (2007) no mercado turístico da Eslovênia, e constituído de quatro dimensões: conhecimento da marca, imagem de marca, qualidade percebida e lealdade à marca.

No entanto, no presente trabalho, substituiu-se a dimensão imagem de marca pela dimensão 'atrativos turísticos', no intuito de reconhecer pontos específicos do local que agregam (ou 
não) valor na percepção do individuo. Esta adaptação foi realizada tendo em vista que o conceito imagem de marca é demasiado amplo e diversificado.

Estruturalmente, o artigo inicia-se com uma breve fundamentação teórica, destacando os aspectos relevantes à compreensão do tema abordado. Em seguida, apresenta-se a metodologia de pesquisa utilizada, a análise e discussão dos resultados do estudo, bem como as limitações e sugestões para futuras pesquisas.

\section{O Customer-based Brand Equity Aplicado a Destinos Turísticos}

Não há consenso entre os estudiosos sobre uma definição única para o conceito valor de marca ou brand equity (BE). O valor de marca é descrito sob distintas abordagens e para diferentes propósitos (AAKER, 1998; KELLER, 2003; LASSAR; MITTAL; SHARMA, 1995; YOO; DONTHU, 1999). A premissa básica do modelo de CBBE é que a força de uma marca está no que os consumidores aprenderam, sentiram, viram e ouviram sobre a marca como resultado de suas experiências ao longo do tempo (KELLER; MACHADO, 2006, p. 36).

A literatura especializada indica que a gestão de marcas não se restringe apenas a produtos e serviços, mas também pode ser aplicada ao marketing de lugares (FREIRE, 2005; HANKINSON, 2004; BOO, 2006). Neste contexto, o conceito de CBBE e suas formas de mensuração vêm sendo aplicados nas pesquisas de turismo e hospitalidade nos últimos anos, ainda que de maneira incipiente (KONECNIK; GARTNER; 2007; BOO; BUSSER; BALOGLU, 2009). Isto decorre da assunção de que a dimensão imagem de destinos já englobe outros construtos, tais como, conhecimento, qualidade e lealdade à marca. Logo, a maioria das pesquisas na área foca exclusivamente o estudo da imagem de destinos. Contudo, Konecnik e Gartner (2007) e Boo (2006) salientam que os destinos turísticos podem ser avaliados não apenas a partir das variáveis da dimensão imagem de destinos, mas também de acordo com o conceito de valor de marca, no qual outras dimensões são analisadas separadamente.

Assim, o modelo conceitual de CBBE proposto e testado por Konecnik (2006) e Konecnik e Gartner (2007) para destinos turísticos, adaptado a este trabalho, abrange quatro variáveis de análise: conhecimento da marca, imagem de marca, qualidade percebida e lealdade à marca, 
conforme segue conceituação nos itens subsequentes. Tal modelo está baseado nos estudos teóricos de Aaker (1998), Keller (1993) e Yoo e Donthu (1999), com adaptações à realidade de destinos turísticos, bem como em trabalhos prévios de imagem de destinos.

\subsection{Conhecimento de marca de destinos turísticos}

Para Aaker (1998, p. 64), “o conhecimento da marca é a capacidade que um comprador potencial tem de reconhecer ou de se recordar de alguma marca como integrante de certa categoria de produtos", pressupondo um elo entre a classe do produto e a marca, e é um atributo chave da marca (de Charnatony, \& McDonald, 2003).

O conhecimento de marca de destinos turísticos tem sido pesquisado prioritariamente sob os tópicos "processo de escolha do destino" ou "processo de decisão de viagem". A maioria dos modelos de comportamento do consumidor em turismo argumenta que o conhecimento do destino é o primeiro e indispensável passo no julgamento e repetição de compra, embora não seja suficiente por si só (KONECNIK, 2006). Pesquisas de imagem de destinos indicam que visitas prévias à localidade, bem como as diferentes fontes de informação sobre a mesma, têm importância capital no conhecimento da marca do destino pelos consumidores (KONECNIK; GARTNER, 2007). O presente estudo adaptou as escalas desenvolvidas e testadas por Konecnik (2006) e Boo (2006) para esta dimensão.

\subsection{Imagem de marca de destinos turísticos $\mathrm{x}$ atrativos turísticos}

Das dimensões existentes em modelos de CBBE, a imagem de marca é a que gera mais desentendimento e falta de convergência entre pesquisadores (KONECNIK, 2006). Aaker (1998, p. 115) define imagem de marca como o "conjunto de associações, usualmente organizadas de alguma forma significativa", de modo que a marca bem posicionada terá uma atraente posição competitiva, quando suportada por outras associações. Keller (1993) afirma ser a imagem de marca as percepções sobre alguma marca refletidas enquanto associações existentes na memória do consumidor.

No entanto, a mensuração da imagem não demonstra uma orientação única. De acordo com Prebensen (2006), a maioria dos estudos de imagem de destino foca as características funcionais observáveis do local, como preços e clima. Outros estudos discutem as características psicológicas do destino, como atmosfera e clima de romance. Há ainda abordagens que analisam as imagens do consumidor segundo duas dimensões: "comum e 
exclusiva”. O único consenso sobre este item é sua importância de acordo com a percepção do consumidor (CAI, 2002; GALLARZA; SAURA; GARCÍA, 2002).

Konecnik e Gartner (2007) propuseram uma escala de mensuração da imagem da marca de destinos turísticos focando prioritariamente a percepção dos turistas em relação aos aspectos funcionais e psicológicos dos atrativos da localidade, tais como, belezas naturais, atrativos culturais, monumentos históricos, opções de compra e lazer, atrativos de aventura, entre outros. As variáveis do estudo foram retiradas da classificação de variáveis baseadas em atributos proposta por Mazanec (1994) e Gallarza et al. (2002) para se avaliar a imagem de destinos turísticos.

O presente estudo adotará esta abordagem, limitando-se a estudar a imagem da marca a partir da percepção do turista em relação aos atrativos turísticos do destino Foz do Iguaçu. Assim, no modelo de CBBE proposto por este trabalho foi utilizada a variável de 'atrativos turísticos' e não imagem de marca, tendo em vista a dificuldade de se medir este constructo na sua real amplitude. Desta forma, entende-se por 'atrativos turísticos' a parte da imagem do destino que avalia especificamente as características locais que podem (ou não) gerarem diferenciais percebidos em relação às atividades e aos locais dedicados ao turismo do destino avaliado. Esta variável inclui, portanto, a investigação sobre a natureza, atividades de entretenimento (matutino e noturno), a infraestrutura do local, o clima, a receptividade do povo local, entre outros.

\subsection{Qualidade percebida em destinos turísticos}

A qualidade de serviços, como é o caso do turismo, é a avaliação completa de determinado serviço que resulta da comparação entre a performance da empresa e a expectativa do consumidor (BITNER, 1990). Este conceito é amplo e inclui o serviço ao consumidor propriamente dito (atendimento as exigências), as operações de entrega e os relacionamentos entre consumidores e funcionários da empresa.

No presente trabalho adotou-se a escala proposta por Boo (2006), na qual foca-se prioritariamente a mensuração da performance ou desempenho dos serviços oferecidos por uma localidade turística. 


\subsection{Lealdade ao destino turístico}

A lealdade pode ser definida enquanto o grau de conexão que determinado consumidor tem em relação a alguma marca, ou como o profundo comprometimento de recompra de algum artigo ou serviço de preferência, mesmo em situações aonde os esforços de marketing de outras empresas induzam à mudança de comportamento (AAKER, 1998; AAKER; JOACHIMSTHALER, 2007)

A literatura apresenta duas diferentes abordagens para este conceito: o modelo determinístico e o modelo estocástico (ODIN; VALETTE-FLORENCE, 1999). No modelo determinístico, a lealdade é tratada prioritariamente enquanto atitude, e, portanto, as medidas são feitas em nível do consumidor individualmente, partindo do pressuposto que existem conceitos antecedentes que influenciam os resultados finais de compra (PRADO, 2004). No modelo estocástico a lealdade é considerada um comportamento, estando sua análise centrada em indicadores de compras repetidas em um grupo de consumidores, sem se considerar os aspectos cognitivos e afetivos envolvidos no processo da compra (ODIN e VALETTEFLORENCE, 1999; PRADO, 2004). Abordagens múltiplas reconhecem que a lealdade é um construto multidimensional - atitudinal e comportamental (PRADO, 2004; CHI, 2005). Tal abordagem será aplicada no presente trabalho.

Assim, a figura 1 apresenta a síntese do Modelo Teórico proposto para a mensuração do CBBE do Destino Foz do Iguaçu. Conforme já comentado, a dimensão imagem de marca será denominada atrativos turísticos, focando prioritariamente a percepção dos turistas em relação aos atrativos turísticos da localidade.

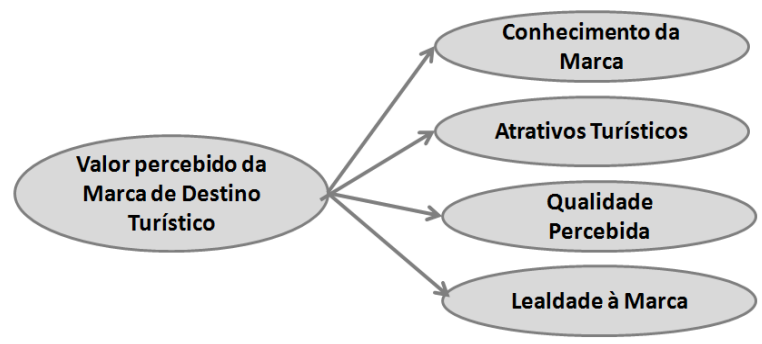

Figura 1 - Modelo Conceitual de CBBE proposto para o Destino Turístico de Foz do Iguaçu Fonte: elaborado pelos autores 


\section{Metodologia}

A pesquisa foi dividida em duas fases. A primeira caracterizou-se pela preparação do instrumento de coleta de dados, a partir da adaptação das escalas propostas por Konecnik (2006), Konecnik e Gartner (2007) e Boo (2006), conforme observado no quadro 1. As escalas foram traduzidas pelo método de tradução reversa.

Na segunda fase o instrumento de coleta de dados preparado foi submetido à pré-teste junto a uma quantidade reduzida de casos $(\mathrm{n}=25)$, em teste piloto, no intuito de checar possíveis inconsistências e equívocos. Em seguida iniciou-se o procedimento descritivo quantitativo transversal, através do método de levantamento ou survey (MALHOTRA, 2004). A população foi constituída por turistas brasileiros que passaram por Foz do Iguaçu. A amostra caracterizou-se por ser não-probabilística, por conveniência. Os respondentes foram abordados no saguão de embarque do aeroporto da cidade.

Quadro 1 - Escalas Aplicadas ao Estudo

\begin{tabular}{|c|c|c|}
\hline Dimensão & Variáveis & Referências \\
\hline \multirow{7}{*}{ Conhecimento } & Algumas características deste destino vêm rapidamente a minha mente & \multirow{7}{*}{$\begin{array}{c}\text { Konecnick } \\
\text { (2006); Boo } \\
\text { (2006) }\end{array}$} \\
\hline & Eu tenho dificuldade de imaginar como seja este destino & \\
\hline & $\begin{array}{l}\text { Eu consigo reconhecer o nome de Foz do Iguaçu entre outros destinos } \\
\text { turísticos }\end{array}$ & \\
\hline & Eu consigo me lembrar da logomarca de Foz do Iguaçu como destino & \\
\hline & Este destino tem um bom nome \& reputação & \\
\hline & Este destino é muito famoso & \\
\hline & $\begin{array}{l}\text { Quando eu penso em natureza, este destino vem a minha mente } \\
\text { rapidamente }\end{array}$ & \\
\hline \multirow{4}{*}{ Lealdade } & Eu gostaria de voltar a visitar este destino no futuro & \multirow{4}{*}{$\begin{array}{l}\text { Konecnick } \\
\text { (2006) }\end{array}$} \\
\hline & Pretendo recomendar este destino para meus amigos & \\
\hline & Foz do Iguaçu proporciona mais benefícios que outros destinos similares & \\
\hline & Foz do Iguaçu é um dos meus destinos preferidos para visitar & \\
\hline \multirow{12}{*}{$\begin{array}{l}\text { Atrativos } \\
\text { Turísticos }\end{array}$} & Este destino apresenta natureza exuberante & \multirow{12}{*}{$\begin{array}{c}\text { Konecnick } \\
\text { (2006); } \\
\text { Konecnik; } \\
\text { Gartner (2007) }\end{array}$} \\
\hline & Este destino contempla obras arquitetônicas exclusivas & \\
\hline & Este destino oferece boa estrutura hoteleira & \\
\hline & Este destino apresenta boas oportunidades para atividades recreativas & \\
\hline & Foz do Iguaçu tem um clima agradável & \\
\hline & Este destino apresenta ambiente relaxante & \\
\hline & Este destina apresenta atrações culturais interessantes & \\
\hline & Este destino oferece boas oportunidades para compras & \\
\hline & Este destino oferece boa vida noturna & \\
\hline & Este destino apresenta atrações históricas interessantes & \\
\hline & Este destino oferece boas oportunidades para turismo de aventura & \\
\hline & Este destino tem atmosfera empolgante & \\
\hline
\end{tabular}




\begin{tabular}{|c|c|c|}
\hline & Este destino apresenta diversidade de etnias e cultura & \\
\hline & A população de Foz do Iguaçu é simpática & \\
\hline & Este destino oferece boas opções gastronômicas & \\
\hline & Este destino oferece boas oportunidades para contato com a natureza & \\
\hline \multirow{4}{*}{ Qualidade } & Este destino apresenta ofertas turísticas de ótima qualidade & \multirow{4}{*}{ Boo (2006) } \\
\hline & Este destino oferece boas experiências & \\
\hline & Eu posso esperar ótimo desempenho das ofertas turísticas deste destino & \\
\hline & Este destino apresenta melhor desempenho que outros destinos similares & \\
\hline
\end{tabular}

Fonte: elaborado pelos autores

Para a coleta de dados, foi desenvolvido um questionário estruturado com escalas de Likert de 5 pontos, sendo 1 discordo totalmente e 5 concordo totalmente. A coleta de dados foi realizada no mês de julho de 2010, através de entrevistas presenciais, no saguão de embarque do aeroporto de Foz do Iguaçu. Dos 303 questionários preenchidos, obteve-se 286 questionários válidos. A seguir são apresentados os resultados obtidos após a coleta de dados.

\section{Análise e Discussão dos Resultados}

Para a análise dos dados coletados aplicou-se prioritariamente as seguintes técnicas estatísticas: análise descritiva, análise fatorial exploratória, análise de agrupamentos; teste $t$ student, análise discriminante e análise do $\mathrm{CBBE}$ por médias. A seguir apresentam-se os principais resultados obtidos.

\subsection{Apresentação dos resultados}

O perfil descritivo da amostra foi de 53,5\% mulheres e 46,5\% homens. A maioria dos respondentes é casada $(61,5 \%)$ e costuma viajar com a família $(79,4 \%)$ ou com amigos (9,8\%). A concentração de idade foi entre 20 e 40 anos (53,5\%), sendo 27,6\% entre 20 e 30 anos, e 25,9\% entre 31 e 40 anos. Quanto à escolaridade dos respondentes, 37,4\% possuem "superior completo" (37,4\%), seguido por "especialização" $(17,8 \%)$ e "superior incompleto (16,4\%). Sobre a renda familiar, 42,7\% estão "acima de R\$ 7.500,00", seguido de 21,3\% “entre R\$ 5.000 e R\$ 7.500”. Quanto ao número de visitas, nota-se grande concentração no item "uma única visita" $(60,8 \%)$.

No intuito de verificar a confiabilidade das escalas utilizadas, foi conduzida uma Análise Fatorial Exploratória (AFE) para cada variável do modelo proposto. Para a extração dos fatores foi realizada a rotação Varimax. Em seguida, foi aplicada a cada variável e às suas 
respectivas dimensões uma análise da consistência interna, verificada pelo coeficiente Alpha de Cronbach. Os valores são apresentados nas tabelas 1 e 2 . Ressalta-se que na tabela 1 é apresentada a média geral de cada variável, onde se percebe maior concordância dos itens, com valores próximos a 4 e pequeno desvio padrão. Já os itens da variável 'atrativos turísticos', detalhados na tabela 2, demonstram nos valores de média e desvio padrão avaliação mais dispersa com valores entre 3 e 4 e desvio padrão entre 0,49 a 1,49.

O construto 'qualidade de destinos' foi mensurado de forma unidimensional, de acordo com os resultados obtidos em pesquisas anteriores (KONECNIK, 2006; KONECNIK; GARTNER, 2007; BOO, 2006). O teste KMO perfaz o valor 0,63, e é aceitável e satisfatório (MALHOTRA, 2004). O índice Alfa de Cronbach ( $\alpha$ ) deste construto foi de 0,59, próximo ao mínimo aceitável proposto por Malhotra (2004), de 0,60.

O construto 'conhecimento do destino' foi mensurado unidimensionalmente, de forma similar à literatura previamente consultada (KONECNIK, 2006; KONECNIK; GARTNER, 2007; BOO, 2006). O item Q4 “dificuldade de imaginar o destino" foi eliminado por apresentar carregamento inferior a 0,30 e por, consequentemente, demonstrar pouco poder de explicação sobre a variável mensurada. O teste KMO resultou no índice 0,70, e o Alfa de Cronbach de 0,61 , sendo ambos satisfatórios.

O construto 'lealdade ao destino' foi mensurado de forma unidimensional, similar ao trabalho de Konecnik (2006). No entanto, o Alfa de Cronbach foi de 0,55 , um pouco abaixo do padrão recomendado por Malhotra (2004) e adotado neste estudo.

Tabela 1 - Análise Fatorial dos Construtos Qualidade Percebida, Lealdade ao Destino e Conhecimento do Destino

\begin{tabular}{l|c|c|c|c|c}
\hline \multicolumn{1}{c|}{ Construtos } & $\begin{array}{c}\text { Média e Desvio } \\
\text { Padrão }\end{array}$ & Fatores & KMO & $\begin{array}{c}\text { Variância } \\
\text { Explicada }\end{array}$ & $\begin{array}{c}\text { Alfa de } \\
\text { Cronbach }\end{array}$ \\
\hline Qualidade Percebida & $4,07(0,56)$ & 1 & 0,63 & $45,93 \%$ & 0,59 \\
\hline Lealdade ao Destino & $4,09(0,54)$ & 1 & 0,65 & $43,91 \%$ & 0,55 \\
\hline Conhecimento do Destino & $4,38(0,48)$ & 1 & 0,70 & $36,15 \%$ & 0,61 \\
\hline
\end{tabular}

Fonte: análise dos dados da pesquisa

Já o construto 'atrativos turísticos' foi mensurado de forma multidimensional. A presença de três dimensões neste construto indica que o turista de Foz do Iguaçu tende a categorizar os 
atrativos da localidade, conforme as especificidades e características dos mesmos. A variância total explicada foi de $46,34 \%$. A primeira dimensão encontrada diz respeito às variáveis relacionadas às belezas naturais da localidade, recebendo, portanto, a denominação natureza $(\alpha=0,70)$, conforme observado na tabela 2.

A segunda dimensão refere-se, de modo geral, aos atrativos relacionados à hospitalidade do destino (serviços de A\&B e hospedagem), recebendo, portanto esta denominação $(\alpha=0,70)$. A terceira dimensão contempla atrativos inerentes a aspectos culturais, e foi intitulada de 'cultura' $(\alpha=0,64)$. O teste KMO das três dimensões perfaz 0,78 , aceitável e adequado (MALHOTRA, 2004).

Tabela 2 - Análise Fatorial do Construto Atrativos Turísticos

\begin{tabular}{|c|c|c|c|c|c|c|}
\hline Dimensão & Itens & $\begin{array}{l}\text { Médias e } \\
\text { Desvio } \\
\text { Padrão }\end{array}$ & Carregamento & $\begin{array}{l}\text { Teste } \\
\text { KMO }\end{array}$ & $\begin{array}{l}\text { Variância } \\
\text { Explicada }\end{array}$ & $\begin{array}{l}\text { Alfa de } \\
\text { Cronbach }\end{array}$ \\
\hline \multirow{6}{*}{ } & (Contato com a natureza) & $4,80(0,49)$ & 0,80 & \multirow{16}{*}{0,78} & \multirow{6}{*}{$27,74 \%$} & \multirow{6}{*}{0,70} \\
\hline & (Natureza exuberante) & $4,83(0,51)$ & 0,70 & & & \\
\hline & (Turismo de Aventura) & $4,50(0,80)$ & 0,66 & & & \\
\hline & (Ambiente relaxante) & $4,21(0,86)$ & 0,49 & & & \\
\hline & (Atmosfera empolgante) & $4,08(0,86)$ & 0,49 & & & \\
\hline & (Atividades recreativas) & $4,13(0,93)$ & 0,47 & & & \\
\hline \multirow{6}{*}{ 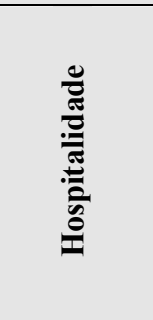 } & (Boa vida noturna) & $3,30(1,11)$ & 0,63 & & \multirow{6}{*}{$10,0 \%$} & \multirow{6}{*}{0,70} \\
\hline & $\begin{array}{l}\text { (Boas opções } \\
\text { gastronômicas) }\end{array}$ & $3,72(1,09)$ & 0,62 & & & \\
\hline & (Boas compras) & $4,17(0,93)$ & 0,61 & & & \\
\hline & (População simpática) & $4,27(0,85)$ & 0,58 & & & \\
\hline & (Boa estrutura hoteleira) & $4,21(0,98)$ & 0,52 & & & \\
\hline & $\begin{array}{l}\text { (Diversidade de etnia e } \\
\text { cultura) }\end{array}$ & $4,34(0,89)$ & 0,47 & & & \\
\hline \multirow{4}{*}{ U } & $\begin{array}{l}\text { (Obras arquitetônicas } \\
\text { exclusivas) }\end{array}$ & $3,46(1,32)$ & 0,78 & & \multirow{4}{*}{$8,6 \%$} & \multirow{4}{*}{0,64} \\
\hline & (Atrações culturais) & $3,69(1,07)$ & 0,68 & & & \\
\hline & (Atrações históricas) & $3,61(1,19)$ & 0,60 & & & \\
\hline & (Clima agradável) & $3,56(1,16)$ & 0,52 & & & \\
\hline
\end{tabular}

Fonte: análise dos dados da pesquisa

Tendo em vista os resultados iniciais descritivos, optou-se por seguir a investigação na busca de diferentes grupos de avaliação sobre o destino de Foz do Iguaçu. Tal sequência de análise foi sugerida pelos índices de desvio padrão das médias encontradas (valores até 1,5). Isto implica em reconhecer que o valor percebido do destino turístico não seja único, mas sim, que 
depende do perfil do turista. Desta forma, foi realizada análise de cluster a partir da avaliação das dimensões de atrativos turísticos para depois checar o índice de CBBE da cidade.

Como resultado, obteve-se a divisão da amostra em dois grupos. O primeiro contemplou 166 respondentes e o segundo, 117, totalizando 283 pessoas. Nota-se que foram excluídos três indivíduos da amostra original (286), em função da incompletude dos dados dos questionários dos mesmos. Foi utilizado o método de cluster $K$-Means com a opção de casos completos na amostra (listwise).

O grupo 1, com 166 respondentes, contempla 58,6\% dos entrevistados. Este grupo é constituído por $53,6 \%$ de pessoas do sexo feminino, com $28,9 \%$ dos respondentes com faixa etária entre 31 a 40 anos, seguido de 27,1\% com faixa etária entre 20 e 30 anos. Deste grupo, $65,1 \%$ das pessoas são casadas, 30,7\% têm nível superior completo, seguido de 19,3\% de respondentes com nível de Especialização. Quanto à renda familiar, 34,9\% apresentam renda acima de $\mathrm{R} \$ 7.500,00$; viajam majoritariamente com a família $(84,3 \%)$ e estavam visitando Foz do Iguaçu pela primeira vez $(60,8 \%)$.

Quanto aos resultados da avaliação deste grupo, melhor detalhados na avaliação do CBBE do destino (item 4.2), verifica-se que o mesmo avalia de forma superior as dimensões do modelo, apresentando a maioria das médias acima ou próximas de 4 . Tal resultado indica que as expectativas turísticas deste grupo foram atendidas satisfatoriamente, e, portanto, o grupo será denominado a partir de agora, Fascinados.

O grupo 2, com 117 respondentes, contempla 41,4\% dos entrevistados classificados. Este grupo é composto por $53,8 \%$ de pessoas do sexo feminino, $56,4 \%$ casados, com $30,8 \%$ de respondentes com faixa etária entre 41 a 50 anos, seguido de $28,2 \%$ entre as faixas etárias de 20 a 30 anos. Quanto ao nível de escolaridade, 46,2\% tem curso superior completo ou mais. A porcentagem de respondentes com valor de renda mensal acima de $\mathrm{R} \$ 7.500,00$ é de 53,8\%. Quanto à rotina de viagens, $71,8 \%$ deste grupo viajam com a família. Em relação ao número de visitas, $61,5 \%$ deste grupo estava visitando Foz do Iguaçu pela primeira vez.

O grupo 2 avalia moderadamente as dimensões do modelo proposto, conforme será discutido com profundidade no item CBBE de Foz do Iguaçu, indicando que suas expectativas turísticas não foram suficientemente atendidas. Por esta razão, este grupo será denominado doravante de Indiferentes. 
Em seguida aplicou-se o teste-t para amostras independentes, de modo a se verificar quais os indicadores do construto atrativos turísticos apresentavam diferença significativa $(p<0,05)$ entre os grupos. Conforme observado na tabela 3, todos os indicadores apresentaram índices com diferenças significativas entre grupos.

De modo geral, verifica-se que ambos os grupos apresentam boas médias para os itens "contato com a natureza", "natureza exuberante" e "turismo de aventura", indicando que apesar da ligeira diferença de médias entre os grupos, a combinação natureza e turismo de aventura são os pontos mais marcantes dos atrativos de Foz do Iguaçu. Além disso, importa ressaltar o fato de a variável "diversidade de etnias e cultura" ser o quarto item melhor avaliado pelos dois grupos, indicando que os mesmos reconhecem e valorizam o atributo do multiculturalismo presente no destino Foz de Iguaçu, com suas 75 distintas etnias.

Tabela 3 - Análise Intergrupos: Dimensão Atrativos Turísticos

\begin{tabular}{|l|c|c|c|c}
\hline \multicolumn{1}{c|}{ Atrativos } & \begin{tabular}{c} 
Grupo Fascinados \\
\cline { 2 - 5 }
\end{tabular} & $\begin{array}{c}\text { Média e } \\
\text { Desvio Padrão }\end{array}$ & $\begin{array}{c}\text { Média e } \\
\text { Desvio Padrão }\end{array}$ & \multirow{2}{*}{ Teste T } \\
\hline (Contato com a Natureza) & $4,94(0,24)$ & $4,61(0,66)$ & 5,15 & $<0,001$ \\
\hline (Natureza Exuberante) & $4,91(0,30)$ & $4,70(0,71)$ & 2,97 & 0,003 \\
\hline (Turismo de Aventura) & $4,73(0,55)$ & $4,18(0,97)$ & 5,58 & $<0,001$ \\
\hline (Diversidade de Etnias e & $4,68(0,57)$ & $3,85(1,04)$ & 7,77 & $<0,001$ \\
\hline Cultura) & $4,60(0,65)$ & $3,65(1,10)$ & 8,33 & $<0,001$ \\
\hline (Boa estrutura hoteleira) & $4,54(0,61)$ & $3,74(0,94)$ & 7,98 & $<0,001$ \\
\hline (Ambiente Relaxante) & $4,52(0,72)$ & $3,93(0,88)$ & 6,08 & $<0,001$ \\
\hline (Populaçao Simpática) & $4,45(0,73)$ & $3,79(1,06)$ & 5,79 & $<0,001$ \\
\hline (Boas Compras) & $4,45(0,75)$ & $3,66(0,98)$ & 7,39 & $<0,001$ \\
\hline (Atividades recreativas) & $4,36(0,66)$ & $3,68(0,95)$ & 6,64 & $<0,001$ \\
\hline (Atmosfera empolgante) & $4,16(0,90)$ & $3,11(1,02)$ & 9,08 & $<0,001$ \\
\hline (Boas opções gastronômicas) & $4,16(0,92)$ & $2,85(1,11)$ & 10,47 & $<0,001$ \\
\hline (Atrações históricas) & $4,10(0,89)$ & $3,11(1,00)$ & 8,69 & $<0,001$ \\
\hline (Atrações culturais) & $3,95(0,97)$ & $3,03(1,20)$ & 6,85 & $<0,001$ \\
\hline (Clima Agradável) & $3,90(1,16)$ & $2,85(1,24)$ & 7,31 & $<0,001$ \\
\hline (Obras arquitetônicas exclusivas) & $3,81(0,88)$ & $2,58(1,01)$ & 10,53 & $<0,001$ \\
\hline (Boa vida noturna) & & & &
\end{tabular}

Os indicadores com menores médias para o grupo Fascinados foram "boa vida noturna" $(3,81)$ e "obras arquitetônicas exclusivas" $(3,90)$, não indicando, no entanto, a partir destes 
índices, grande insatisfação quanto a estas variáveis, se considerarmos a escala de likert aplicada de 5 pontos.

Quanto ao grupo Indiferentes, nota-se a percepção mais negativa deste grupo em relação a todos os indicadores. Sobre o item "boa vida noturna", como este grupo apresenta 43,6\% de pessoas solteiras, divorciadas ou viúvas, contra 34\% do grupo Fascinados, isto possivelmente pode afetar a expectativa dos integrantes do grupo quanto às atividades noturnas. Além disso, $25,6 \%$ do grupo Indiferentes viajam sozinhos ou com amigos, contra 12,6\% do grupo Fascinados, podendo também afetar as expectativas do grupo Indiferentes quanto a este tipo de atrativo. Além disso, o melhor nível de renda deste grupo também pode ter influenciado a sua percepção quanto aos itens "atrações culturais" e "obras arquitetônicas" da localidade, tendo em vista que eles possuem maiores chances de viajar para outros destinos, fato que torna a comparação com Foz mais 'exigente'.

Assim, a partir destes dados, infere-se a possibilidade de que as diferenças nas características demográficas da amostra influenciaram a percepção dos respondentes quanto aos atrativos de Foz do Iguaçu e, consequentemente, a avaliação do valor de marca da localidade. A existência de distintos grupos turísticos no destino torna-se, assim, relevante aspecto a ser considerado na gestão do marketing do destino Foz do Iguaçu. Esta constatação confere parte da originalidade deste estudo.

Foi ainda conduzida uma análise discriminante no intuito de reconhecer o poder de explicação dos itens geradores dos grupos, bem como identificar a função determinante dos grupos. Para isto, foi utilizado o método stepwise no intuito de checar a contribuição na entrada de cada variável analisada. Assim, foi seguida a regra de seleção da etapa que congrega o menor índice de Wilk's lambda. De acordo com os dados obtidos, a função discriminante foi definida por: função 1: Eigenvalue $=2,032$, variância $(99,0 \%)$, canonical correlation $=0,81$, Wilk's lambda $0,33, \mathrm{X}^{2}=306,148, \mathrm{p}<0,001$. Os valores comprovam a relevância da avaliação das dimensões de atrativos turísticos como fonte de diferenciação entre os respondentes da pesquisa. 


\subsection{O CBBE do destino Foz do Iguaçu}

Finalmente, para avaliar o valor percebido de marca do destino turístico de Foz do Iguaçu, verificaram-se as médias finais de cada dimensão para cada subgrupo da amostra, conforme a tabela 4 .

Tabela 4 - O CBBE de Foz do Iguaçu para Ambos os Grupos

\begin{tabular}{l|c|c|c|c}
\hline \multicolumn{1}{c|}{ Dimensões do Modelo } & $\begin{array}{c}\text { Grupo } \\
\text { Fascinados }\end{array}$ & $\begin{array}{c}\text { Grupo } \\
\text { Indiferentes }\end{array}$ & Teste T & Valor-p \\
\hline Atrativos - Natureza & 4,65 & 4,09 & 11,52 & $<0,001$ \\
\hline Atrativos - Hospitalidade & 4,36 & 3,48 & 16,36 & $<0,001$ \\
\hline Atrativos - Cultura & 4,02 & 2,95 & 14,13 & $<0,001$ \\
\hline Conhecimento & 4,53 & 3,98 & 10,17 & $<0,001$ \\
\hline Lealdade & 4,29 & 3,80 & 8,28 & $<0,001$ \\
\hline Qualidade & 4,26 & 3,79 & 7,37 & $<0,001$ \\
\cline { 1 - 1 } & 4,37 & 3,70 & 17,223 & $<0,001$ \\
\hline
\end{tabular}

Fonte: análise dos dados da pesquisa

Observa-se que o maior índice das médias recai na dimensão atrativos natureza. Isso resulta, prioritariamente, das altas médias direcionadas às variáveis "contato com a natureza", "natureza exuberante" e "turismo de aventura", combinados com "ambiente relaxante" e "boa opção de atividades recreativas". Assim, apesar da diferença de médias entre os grupos, a imagem mais forte de Foz do Iguaçu para ambos os grupos é a sua vocação para atrativos que envolvam a natureza, aonde é possível desenvolver atividades de aventura e de caráter recreativo ao ar livre, despertando a percepção de ser Foz do Iguaçu um destino com ambiente relaxante e / ou adequado para minimizar o estresse do dia-a-dia.

A dimensão conhecimento foi a segunda de maior destaque no CBBE de Foz do Iguaçu também para ambos os grupos. O conhecimento na percepção de ambos os grupos consiste prioritariamente da lembrança das características da localidade, o reconhecimento de seu nome enquanto destino turístico, e a percepção de ser um destino famoso. Tais resultados evidenciam a boa familiaridade dos respondentes em relação à localidade, o que pode influenciar positivamente no nível de simpatia dos mesmos quanto ao destino (KELLER, 1993). Contudo, a diferença das médias entre os grupos demonstra que esta realidade é mais presente na percepção dos respondentes do grupo Fascinados. No entanto, ressalta-se que o item "lembrança da logomarca" foi a pior avaliada por ambos os grupos. 
Para o grupo Fascinados, as variáveis dos atrativos hospitalidade ficaram em terceiro lugar com média de 4,36. Para este grupo, a imagem desta dimensão é uma combinação de boa estrutura hoteleira, população simpática, diversidade de etnias e bom local para compras, ou seja, relaciona-se em parte aos atrativos mais objetivos da localidade, e em parte a percepção de aspectos mais subjetivos, como população simpática. A média é significativa, considerando a escala utilizada de 5 pontos. A dimensão lealdade, com média de 4,29, é representada prioritariamente pela intenção de indicar o destino a amigos e voltar a visitar. Estes índices representam altas médias tanto para os aspectos atitudinais quanto aos aspectos comportamentais da lealdade. Os resultados reforçam também a literatura estudada, preconizando que altos níveis de conhecimento de marca, bem como percepção positiva da imagem da localidade, como é o caso do grupo Fascinados, podem influenciar positivamente o nível de lealdade, principalmente quanto à tendência de recomendar o destino a terceiros (KONECNIK, 2006).

A dimensão qualidade, do ponto de vista do grupo Fascinados, obteve média de 4,29 e resulta prioritariamente da percepção de se poder ter boas experiências no destino, no qual se encontram produtos e serviços turísticos de ótima qualidade. Por último, a dimensão 'cultura' obteve média 4,02 no grupo Fascinados, representada principalmente pela percepção do destino oferecer atrações históricas, culturais e obras arquitetônicas exclusivas. Esta dimensão é a que menos influencia o valor de marca do grupo Indiferentes.

Já para o grupo Indiferentes, as variáveis lealdade $(3,80)$ e qualidade $(3,79)$ demonstram valores médios com pequeno resquício de concordância, tendo em vista que o valor 3 da escala confere a interpretação de "nem concordo/nem discordo", fato que reforça a avaliação indiferente deste grupos sobre estes itens. Situação semelhante ocorre para o item hospitalidade de Foz do Iguaçu. As variáveis que contribuíram mais negativamente para a média geral desta dimensão foram as opções gastronômicas e boa vida noturna. A dimensão 'cultura' é a que apresenta a menor média $(2,95)$ do modelo, reforçando a indiferença percebida neste item.

Possível explicação para esta diferença de percepção entre os grupos está no fato de o grupo Indiferentes ter um padrão social e de escolaridade superior ao grupo Fascinados, podendo então ter experiências turísticas mais diversificadas e qualificadas se comparadas ao primeiro, aumentando, assim, o nível de exigência e expectativa dos respondentes deste grupo quanto a 
certos indicadores, tais como, estrutura hoteleira e boas opções gastronômicas. Além disso, o grupo Indiferentes tem maior índice de pessoas solteiras, se comparado ao grupo Fascinados, podendo afetar a avaliação dos atrativos noturnos da localidade. Por fim, a média geral de CBBE para cada grupo (Fascinados $=4,37$ e Indiferentes $=3,70$ ) evidencia que o valor percebido do destino turístico depende do perfil do turista.

\subsection{Discussão dos resultados sobre o CBBE de destinos turísticos}

Os principais achados deste estudo podem ser agrupados em 3 principais itens. Primeiro, sob a construção do CBBE de destinos turísticos considerando a análise conjunta das 4 variáveis em estudo (conhecimento do destino, lealdade ao destino, atrativos turísticos e qualidade percebida), fato que é original a este estudo. Estudos anteriores consideraram diferentes agrupamentos do CBBE, como é o caso dos trabalhos de Konecnik e Gartner (2007), que adotaram um modelo conceitual constituído das dimensões imagem da marca, conhecimento de marca, qualidade percebida e lealdade à marca, e também da pesquisa de Boo (2006), que acrescentou ao modelo de Konecnik e Gartner (2007) a dimensão valor de marca de destinos turísticos. Em especial, a contribuição do item atrativos turísticos no modelo fica evidente quando a avaliação das dimensões encontradas (cultura, hospitalidade e natureza) demonstra tamanha disparidade de opiniões, capaz de gerar grupos distintos de avaliação. Além disto, este item aponta elementos imprescindíveis na avaliação de um destino turístico sob a perspectiva da formação das expectativas dos turistas. O primeiro, natureza, refere-se aos elementos de ordem natural, única e exclusiva da região. Já a hospitalidade depende do preparo da infraestrutura da região, bem como das pessoas que trabalham com o turismo da região. Este item permite ação de investimento pontual e treinamento entre as pessoas envolvidas no atendimento ao turista. $\mathrm{O}$ item cultura depende da história, da tradição e da capacidade da região oferecer boas opções de entretenimento.

Segundo, pela condição de avaliar o valor da marca do destino turístico considerando a diversidade da amostra e, portanto, utilizando a análise de grupos. Neste caso foi possível perceber que nem todos os turistas avaliam a cidade de igual forma. Há uma relação direta com a expectativa dos indivíduos, bem como sua condição de viajante. Quanto mais lugares se conhecem mais crítica passa a ser a comparação de diferentes locais. Estudos anteriores não relevaram em suas análises tal condição (KONECNIK, 2006; KONECNIK; GARTNER, 2007; BOO, 2006). Portanto, sugere-se a partir deste estudo que o valor de marca de destinos 
turísticos contemple ao menos dois perfis de turistas cada vez mais comuns, dado a condição de mercado atual, a qual favorece o desenvolvimento do turismo: (1) os que têm menor histórico de viagens e, portanto, estão mais propensos ao encantamento com o local visitado, fato que favorece a indicação para outras pessoas e (2) os que têm maior experiência com viagens e, por este motivo, são mais críticos e exigentes.

Em terceiro, fica evidente a importância da natureza como elemento de destaque à cidade de Foz do Iguaçu. Ambos os grupos conferem pontos importantes à cidade como a exuberância da natureza. Em contrapartida, apesar do 'conhecimento da cidade' ser um item importante, a lembrança da logomarca da cidade é apontada com baixos índices de média. Portanto, sugerese que o marketing de lugares seja empregado de forma única e consistente na divulgação do destino turístico.

\section{Considerações Finais, Implicações e Limitações}

De acordo com o estudo realizado, foi possível perceber diferenças significativas entre os respondentes quanto à percepção das variáveis analisadas pelo modelo proposto, permitindo a divisão da amostra em dois subgrupos, a partir da dimensão atrativos turísticos: um que avalia muito positivamente a localidade, e outro com percepção indiferente do destino. Tal fato sugere a reflexão por parte dos gestores do destino sobre a possibilidade de se aplicar diferentes estratégias de marketing para cada grupo, principalmente no que se refere aos serviços de hospedagem e opções gastronômicas, bem como aos atrativos relacionados à vida noturna e aspectos culturais. Os resultados obtidos indicaram percepção mais negativa dos turistas solteiros e com maior renda quanto a estes quesitos.

O estudo também evidenciou que os atrativos de Foz do Iguaçu são percebidos em 3 categorias distintas, a saber: natureza, hospitalidade e cultura. Destas, a dimensão natureza é a que recebeu a maior pontuação, indicando que ambos os grupos reconhecem a força destes atrativos no valor de marca do destino, podendo-se inferir, a partir disto, que as características peculiares da natureza da localidade diferenciam Foz do Iguaçu no mercado turístico, proporcionando-lhe, possivelmente, vantagem competitiva neste aspecto. Quanto às demais dimensões do construto, a percepção entre os grupos é distinta. Para o grupo Fascinados, os construtos hospitalidade e cultura são significativos, com médias igual ou superior ao valor 4 . 
Já para o grupo Indiferentes tais dimensões têm avaliação próximas ou menor ao valor 3, evidenciando que as diferenças socioeconômicas e demográficas entre os grupos altera o nível de expectativa dos mesmos, principalmente quanto aos aspectos tangíveis da infraestrutura da localidade, tais como, opções de serviços de alimentos e bebidas e estrutura hoteleira.

Quanto à dimensão conhecimento do destino, verifica-se que a marca Foz do Iguaçu é reconhecida, rememorada e destacada na mente dos turistas entrevistados enquanto destino turístico de renome, minimizando, portanto, a necessidade de grandes esforços de marketing neste item. No entanto, merece atenção por parte dos gestores do destino a variável "lembrança da logomarca", a pior avaliada por ambos os grupos estudados. Tal fato sugere a necessidade de maiores investimentos de marketing neste quesito, uma vez que é consenso que elementos visuais têm importante papel na construção do valor da marca, especialmente no que se refere à lembrança de marca (KELLER; MACHADO, 2006).

Já as médias do construto lealdade indicam a possibilidade de atração de novos turistas a partir da propaganda boca-a-boca espontânea gerada pelos turistas satisfeitos, expressa na intenção dos respondentes em recomendar o destino a amigos, especialmente sobre o grupo Fascinados.

A avaliação do construto qualidade percebida diferenciou-se entre os grupos. O grupo constituído prioritariamente por famílias e com renda familiar mais baixa (Fascinados) apresentou médias mais altas, indicando que as expectativas destes respondentes foram atendidas plenamente. Já no segundo grupo a avaliação não foi tão positiva, ainda que satisfatória de modo geral. No entanto, para ambos os grupos, as médias obtidas no valor de marca de Foz do Iguaçu são bastante expressivas, ao se considerar a escala de Likert aplicada de 5 pontos. Para o grupo Fascinados, a média geral de todas as variáveis foi de 4,40, enquanto que para os Indiferentes foi de 3,68.

Do ponto de vista teórico, a contribuição deste estudo diz respeito à mensuração do valor percebido de marca de um destino turístico, conceito ainda pouco explorado nas pesquisas da área de turismo. $\mathrm{O}$ modelo adotado considerou quatro dimensões separadamente, minimizando a possibilidade de sobreposição de construtos, bem como facilitando o refinamento das escalas. Neste sentido, a denominação do construto imagem de marca foi 
adaptada para atrativos turísticos, com o intuito de melhor representar o conteúdo mensurado nesta variável.

Sugere-se a replicação deste estudo em outros destinos turísticos, considerando, no entanto, os possíveis distintos perfis de públicos que trafegam em uma localidade. É razoável inferir que outros destinos turísticos contemplem também públicos com diferentes percepções. Quanto às escalas utilizadas, futuros avanços e refinamentos podem ser interessantes.

\section{Referências}

AAKER, David. Marcas - Brand Equity: gerenciando o valor da marca. Rio de Janeiro: Elsevier Editora Ltda, 1998.

AAKER, David; JOACHIMSTHALER, Erich. Como construir marcas líderes. Porto Alegre: Bookman, 2007

BITNER, M. J.; BOOMS, B. H.; TETREAULT, M. S. The service encounter: diagnosing favorable and unfavorable incidents. Journal of Marketing, v. 54, n. 1, p. 71-84, Jan. 1990.

BOO, Soyoung. Multidimensional Model of Destination Brands: an application of customer-based brand equity. Dissertação de Doutorado. Universidade de Nevada, Las Vegas, USA, 2006.

BOO, Soyoung; BUSSER, James; BALOGLU, Seyhmus. A Model of customer-based brand equity and its application to multiple destinations. Tourism Management, p. 219-231, 2009.

CAI, L. Cooperative branding for rural destination. Annals of Tourism Research, 2002.

CHI, G. A Study of Developing Destination Model. Tese de Doutorado. Oklahoma State University, 2005.

EMBRATUR. Anuário Estatístico de Turismo 2009. Volume 36, ano-base 2008. Disponível em: www.turismo.gov.br/dados_fatos/. Acesso em: 27.01.2010.

FREIRE, João. “Other tourists': A critical factor for a geo-brand-building process. Place Branding, v. 2, 2005

GALLARZA, M; SAURA, I.; GARCÍA, H.; Destination Image: Towards a conceptual framework. Annals of Tourism Research, v. 29, n. 1, 2002.

HAIR JUNIOR, J.F. Análise Multivariada de dados. 5 ed. Porto Alegre: Bookman, 2005

HANKINSON, Graham. Relational networks brands: towards a conceptual model of place brands. Journal of Vacation Marketing, v. 10, n. 2, p. 109-121, 2004.

KAPFERER, J. As marcas, capital da empresa: criar e desenvolver marcas fortes. Porto Alegre: Bookman, 2003.

KELLER, Kevin Lane. Conceptualizing, Measuring, and Managing Customer-based Brand Equity. Journal of Marketing. Vol. 57, 1993.

KELLER, Kevin Lane; MACHADO, Marcos. Gestão Estratégica de Marcas. São Paulo, Pearson Education, 2006.

KONECNIK, M.; GARTNER, W. Customer-based brand equity for a destination. Annals of Tourism Research, Vol. 34, No 2, pp 400-421, 2007. 
KONECNIK, M. Croatian-based brand equity for Slovenia as a tourism destination. Economic and Business Review for Central and South - Eastern Europe; v. 8, n. 1, 2006.

LASSAR; MITTAL; SHARMA. Measuring customer-basef brand equity. The Journal of Consumer Marketing, 1995.

MALHOTRA, N. K. Pesquisa de Marketing: uma orientação aplicada. $3^{a}$ edição. Porto Alegre: Bookman Companhia Editora, 2004.

MORGAN, Nigel, PRITCHARD, Annette, PIGGOTT, Rachel. New Zealand, 100\% pure. The creation of a powerful niche destination brand. Journal of Brand Management, v. 9, p. 33, 2002.

O'LEARY, Sinéad; DEEGAN, Jim. 2005. Ireland's image as a tourism destination in France: attribute importance and performance. Journal of Travel Research, v.43, p. 247- 256, fev.

ODIN, Y; ODIN, N; VALLETE-FLORENCE, P. Conceptual and Operational Aspects Brand Loyalty: An empirical investigation. Journal of Business Research, 1999.

PRADO, Paulo. A Avaliação do Relacionamento sob a Ótica do Cliente: um Estudo em Bancos de Varejo. Tese de Doutorado. Fundação Getúlio Vargas, 2004.

PREBENSEN, Nina. Exploring Tourists' Images of a Distant Destination. Tourism Management, 2006.

RITCHIE, J.R. Brent; CROUCH, Geoffrey I. The competitive destination: a sustainability perspective. University of Calgary: Canada, 2003.

YOO, B.; DONTHU, N. Developing and Validating a multidimensional customer-based brand equity scale. Journal of Business Research, 1999.

\section{Recebido em: 08/08/2011}

Aprovado em: 11/11/2011 